\title{
BLOOD TRANSFUSION IN OBSTETRICS AND GYNECOLOGY: A RETROSPECTIVE ANALYSIS IN GOVERNMENT NASEERULLAH BABAR HOSPITAL PESHAWAR
}

\author{
Nadia Kashif ${ }^{1}$, Aneela Ambreen ${ }^{2}$, Afshan Ahsan $^{3}$
}

\section{ABSTRACT:}

\section{OBJECTIVES:}

To evaluate the indications of blood transfusion in the Obstetrics and Gynecology Department of Government NaseerUllah Khan Babar Memorial Hospital.

\section{METHODOLOGY:}

This retrospective observational study was performed on indoor gynecology and obstetrics patients for the period of one year, a total of 100 patients were included in this study that received blood transfusion. Samples were collected by non-random convenience sampling after getting approval from the hospital ethical committee. Data was analyzed by using SPSS version 20.

\section{RESULTS:}

In this study a total of 100 patients who received blood transfusion were analyzed, out of 100 patients $78 \%$ of patients received transfusion due to obstetrical causes and 22\% patients got transfused for gynecological causes. Most common blood group transfused was $B+$ and $O+$ and mean hemoglobin level at which patients received blood transfusion was $9.7 \mathrm{~g} / \mathrm{dl}$. Blood components preparation can provide components to treat two to three patients from a single donor. The use of packed cell transfusion should be promoted instead of whole blood transfusion that is not even needed in most of the cases.

\section{CONCLUSION:}

Blood transfusion practice has been used aggressively in gynecology and obstetrics in some cases even without proper indications. There is a need to modify this practice by correcting anemia through drugs to avoid the inappropriate use of blood. Use of blood components should be encouraged.

KEYWORDS: Blood Transfusion, Blood Components, Obstetrical Hemorrhage

\section{How to cite this article:}

Kashif N, Ambreen A, Ahsan A. Blood Transfusion in Obstetrics And Gynecology: A Retrospective Analysis in Government Naseerullah Babar Hospital Peshawar. J Gandhara Med Dent Sci. 2022;9(1): 20-23

https://doi.org/10.37762/jgmds.9-1.141

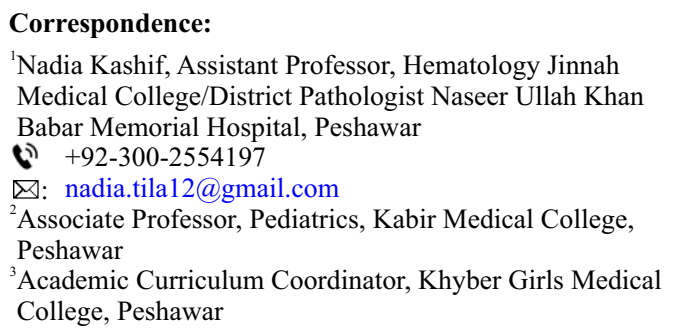

${ }^{1}$ Nadia Kashif, Assistant Professor, Hematology Jinnah Medical College/District Pathologist Naseer Ullah Khan Babar Memorial Hospital, Peshawar (i) +92-300-2554197

$\nabla:$ nadia.tila12@gmail.com

${ }^{2}$ Associate Professor, Pediatrics, Kabir Medical College, Peshawar

${ }^{3}$ Academic Curriculum Coordinator, Khyber Girls Medical College, Peshawar

\section{INTRODUCTION:}

This study was conducted keeping in view identifying and highlighting the existing transfusion practices in gynecology and obstetrics department of this hospital, including the need of blood transfusion and the allergic reaction associated with blood transfusion. In obstetrics, timely decisions about blood transfusion can be lifesaving intervention. Therefore, obstetricians and gynecologists should be aware of the potential 
risks associated with blood transfusion ${ }^{1-3}$. In usual practice Obstetricians and gynecologists make the most of blood transfusion. Anemia is a common finding during pregnancy. Platelets are activated during the last trimester of pregnancy along with the suppression of fibrinolysis that leads to increased risk of thrombocytopenia; consequently the females in their last trimester are at increased risk of hemorrhage; mostly during labor ${ }^{4,5}$. Major cause of maternal mortality worldwide is obstetrical hemorrhage. According to WHO report over a thousand of all maternal deaths are due to obstetrical hemorrhage. Main causes of hemorrhage in obstetrics and gynecology are placenta previa, placenta abruption, postpartum hemorrhage, menorrhagia and dysfunctional uterine bleeding. Placental blood flow increases during term raises to about $700 \mathrm{ml} / \mathrm{min}$ that further increases the risk of bleeding that could be unexpected and uncontrolled. Blood transfusion is potentially a lifesaving procedure. Even though thorough care is needed in selecting blood donors, processing, storage and blood transfusion, serious transfusion associated complications may result. Physicians should ensure the right indication of blood transfusion and should be aware of standard transfusion practices ${ }^{6}$. Inappropriate use of blood transfusions has led to major morbidity and mortality. Hence, the right choice for transfusion is the use of the right product, for the right patient in the right dose at the right time for the right indication ${ }^{7,8}$. The need for blood transfusion arises whenever the hemoglobin level of an individual is reduced to $6 \mathrm{gm} / \mathrm{dl}$, and it is seldom needed when the hemoglobin level is above $10 \mathrm{gm} / \mathrm{dl}^{9}$. This is to be understood that patients with acute hemorrhage can have normal hemoglobin; therefore, evaluation of the patient by the clinician during such circumstances is required to assess the need of blood transfusion. During the last three decades a general trend in the reduction of blood transfusion is observed in obstetrics and gynecology. The cause for this trend is mainly risk associated with blood transfusion especially transfusiontransmitted infections and improved pharmacological, surgical and mechanical innovations to decrease blood loss and iron supplementation for high-risk people ${ }^{10,11}$. This study was conducted to find out the main causes of blood transfusion in the gynecology and obstetrics department and to highlight the use of blood components instead of whole blood transfusion. Secondly, blood transfusion practice should be done according to WHO criteria to minimize blood transfusion practice and promote iron supplements and intravenous iron administration instead of whole blood transfusion.

\section{METHODOLOGY:}

This retrospective observational study was performed in Government NaseerUllah Babar Memorial Hospital after getting approval from hospital ethical committee, for the period of one year that is during 2020 and total 100 patients were assessed who received blood transfusion during their stay in hospital, data obtained from admission charts of patients and blood bank registers. Samples were selected by using non-random convenience sampling techniques. Data was analyzed by using SPSS version 20. All obstetrical and gynecological patients who received blood transfusion were included in this study. Patients who received blood transfusion but had comorbid conditions were excluded in this study.

\section{RESULTS:}

In this study a total of 100 gynecology and obstetrics patients who were admitted in gynecology and obstetrics wards were analyzed who got blood transfusions. According to results obtained out of 100 patients who received blood transfusions, $78 \%$ of patients were grouped into obstetrical patients and remaining $22 \%$ of patients were grouped into gynecological patients as shown in Table 1.

Table 1: Mean Hemoglobin Level, Mean Age of Blood

Transfusion in Obstetrics and Gynecology Patients

\begin{tabular}{|l|c|}
\hline Mean HB Level Before Transfusion & $9.7 \mathrm{~g} / \mathrm{dl}$ \\
\hline $\begin{array}{l}\text { Frequency of Obstetrical Patients Got } \\
\text { Transfused }\end{array}$ & $78 \%$ \\
\hline $\begin{array}{l}\text { Frequency of Gynecological Patients Got } \\
\text { Transfused }\end{array}$ & $22 \%$ \\
\hline Mean Age of Transfused Patients & $\begin{array}{c}31 \\
\text { Years }\end{array}$ \\
\hline
\end{tabular}

In this study the most common blood group transfused was $\mathrm{B}+$ that is about $32 \%$ out of 100 transfusions, $\mathrm{O}+$ that is $29 \%$ of total transfusion and $\mathrm{A}+$, which is $28 \%$ of total transfusion. The least common blood group transfused was $\mathrm{O}$ - and $\mathrm{B}$ - that were $2 \%$ each. Thus $\mathrm{B}+$ and $\mathrm{O}+$ are the most common blood group transfused in study patients as clear from Figure 1. 


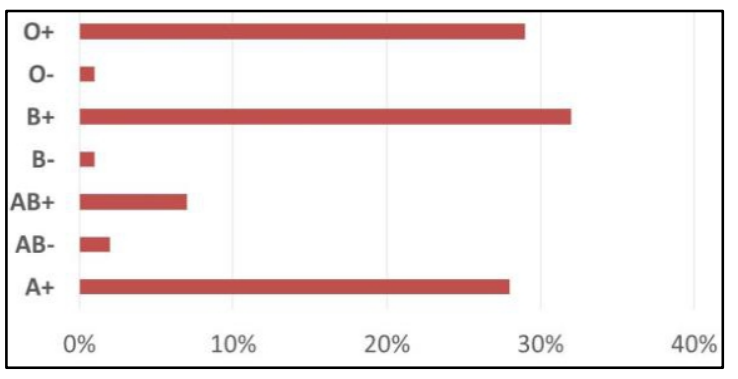

Figure 1: Most Common Blood Group Transfused

In our study we also observed the frequencies of different obstetrical and gynecological disorders which were the cause of blood transfusion. According to the results obtained the most common cause of blood transfusion found was pregnancy with anemia out of 100 patients $25 \%$ of patients who received blood transfusion had pregnancy with anemia, second common cause for blood transfusion were emergency cesarean section and total abdominal hysterectomy $15 \%$ each, while elective C-section cases were $8 \%$ who needed blood transfusion. Other gynecological and obstetric causes in which patients received blood transfusion ranged from $3 \%$ to $1 \%$ as shown in Table 2 below.

Table 2: Common Causes of Blood Transfusion in Obstetrics \& Gynecology

\begin{tabular}{|l|c|}
\hline \multicolumn{2}{|c|}{ Common Causes of Blood Transfusions } \\
\hline Pregnancy with Anemia & $25 \%$ \\
\hline TAH & $15 \%$ \\
\hline Emergency C-Section & $15 \%$ \\
\hline Elective C-Section & $8 \%$ \\
\hline NVD & $3 \%$ \\
\hline E n C & $2 \%$ \\
\hline IUD & $4 \%$ \\
\hline PG Breech & $2 \%$ \\
\hline Pregnancy with PV Leak & $2 \%$ \\
\hline A/P Repair & $1 \%$ \\
\hline Ectopic Pregnancy & $1 \%$ \\
\hline FTP PG & $1 \%$ \\
\hline Hydroceph Baby & $1 \%$ \\
\hline Incomplete Abortion & $1 \%$ \\
\hline Menorrhagia/TAH & $2 \%$ \\
\hline Missed Abortion & $1 \%$ \\
\hline Myomectomy & $1 \%$ \\
\hline NVD with PPH & $1 \%$ \\
\hline PG with Bleeding & $1 \%$ \\
\hline PG with H.Mole & $1 \%$ \\
\hline Post Dates for Induction & $1 \%$ \\
\hline Post TAH with Infected Wound & $1 \%$ \\
\hline Postnatal Anemia & $1 \%$ \\
\hline Postnatal/PPH & $1 \%$ \\
\hline Precious Pregnancy & $1 \%$ \\
\hline Pregnancy with CPD & $1 \%$ \\
\hline Pregnancy with Fever & $1 \%$ \\
\hline Pregnancy with Hyper Emesis & $1 \%$ \\
\hline Pregnancy with UTI & $1 \%$ \\
\hline Retained Placenta & $1 \%$ \\
\hline TAH Fibroids & $1 \%$ \\
\hline Vaginal Hysterectomy & $1 \%$ \\
\hline
\end{tabular}

\section{DISCUSSION:}

In hospitals where there is fully functional gynecology and obstetrical specialties proper and well-developed blood banks are mandatory. As observed in this study, moderate to severe degree of anemia is common findings in most study patients. Major cause of morbidity and mortality in females admitted in gynecology and obstetrics department is anemia that could be nutritional or hemorrhagic. In obstetrics as the pregnancy advances and progresses to term the need of blood transfusion for treating anemia increases. According to Royal College of Obstetrics and Gynecology guidelines, ${ }^{12,13}$ recommendation for blood transfusion is rare if hemoglobin level is $>10.0 \mathrm{~g} / \mathrm{dl}$ and patient vitals are normal, however it is always needed if hemoglobin level of patients drop to $<6.0 \mathrm{~g} / \mathrm{dl}$. Majority of patients in this study had hemoglobin level $9.7 \mathrm{~g} / \mathrm{dl}$ or below at the time of hospitalization as shown in Table 1. In a study conducted in Pakistan about the blood transfusion practices in cesarean section patients, indication of blood transfusion was low hemoglobin level followed by ongoing bleeding. The results of our study coincide with the findings of research conducted by Ismail et al that whole blood was transfused for correction of anemia in pregnant and post-natal patients. In current study pre-operative correction of low hemoglobin level was common findings in dysfunctional uterine bleeding patients. Usually the standard therapy for correction of low hemoglobin levels in pre operative patients is oral or intravenous iron supplementations. According to WHO report transfusions are frequently given to increase hemoglobin levels of patients prior to surgery and to reduce patient stay in hospital after surgery. These are not valid reasons for transfusions ${ }^{14,15}$. In some cases whole blood transfusion is not needed at all but due to lack of facilities in blood banks for the preparation of blood components, whole blood transfusion is common practice in our settings. Blood components preparation can provide components to treat two to three patients from single donor ${ }^{14,16}$. The use of packed cell transfusion should be promoted instead of whole blood transfusion that is not even needed in most of the cases. Another study was conducted in the UK that was a retrospective analysis of transfusion outcome in pregnant patients at tertiary obstetric center ${ }^{17}$. In that study which was also for the period of one year 74 patients received blood transfusion and mean hemoglobin of the patient's received transfusion was $7.6 \mathrm{~g} / \mathrm{dl}$ and in $34 \%$ of cases there was no specific indication for blood transfusion. As 
in our study there was no proper documentation of indication for blood transfusion. There was no consent of the patient or relative for blood transfusion. Thus, it is clear from literature review and studies mentioned above that blood transfusion and its hazards could be prevented in antenatal and pre-operative patients using intravenous or oral iron administration ${ }^{18}$.

\section{CONCLUSION:}

Blood transfusion practices should be reformed by switching towards the use of oral or intravenous iron administration in early pregnancy and preoperative patients to avoid inappropriate use of blood transfusion. It is recommended to formulate and display proper guidelines for blood transfusion on an institutional basis.

\section{CONFLICT OF INTEREST: None}

\section{FUNDING SOURCES: None}

\section{REFERENCES:}

1. Singh S, Sinha P, Yadav G, Gupta U, Tyagi P. Transfusion practices in obstetrics and gynecology in a tertiary care center. Int J Reprod Contracept Obstet Gynecol 2016:5:831-4.

2. Hornis CM, Vigh RS, Zabo JF, Dierking EL. Transfusion error in the gynecology patient: a case review with analysis. Vignettes Patient Saf. 2018;3:125-39.

3. Morrison JC, Parrish MR. Anemia associated with pregnancy. Global Libr Women's Med. 2016.

4. Ciobanu AM, Colibaba S, Cimpoca B, Peltecu G, Panaitescu AM. Thrombocytopenia in Pregnancy. Maedica (Bucur). 2016;11(1):55-60.

5. Agarwala R, Millar CM, Campbell JP. Haemostatic disorders in pregnancy. BJA Educ. 2020;20(5):150-7.

6. Shrivastava M, Shah N, Navaid S, Agarwal K, Sharma G. Blood donor selection and deferral pattern as an important tool for blood safety in a tertiary care hospital. Asian J Transfus Sci. 2016;10(2):122-6.

7. Lee SS, Cheung EKH, Leung JNS, Lee CK. Noncompliance to infectious disease $\begin{array}{lccc}\text { deferral criteria among Hong } & \text { Kong's } \\ \text { blood } & \text { donors. } & \text { Vox } & \text { Sang . }\end{array}$ 2017;112(5):425-33.

8. Harris JC, Crookston KP. Blood Product Safety. In: StatPearls [Internet]. Treasure Island (FL): StatPearls Publishing; 2021. Available from: https://www.ncbi.nlm.nih.gov/books/NBK 539826/

9. Kashefi P, Rahmani A, Khalifesoltani M. Changes in the hemoglobin level after one unit of packed red blood cell transfusion in intensive care unit patients. J Res Med Sci. 2018;23:85.

10. Singh RK, Anne S, Ravindran SP. Changing trends of blood transfusion requirement in obstetrics and gynaecology. Int $\mathrm{J}$ Reprod Contracept Obstet Gynecol. 2018;7:2018-22.

11. Fong IW. Blood transfusion-associated infections in the twenty-first century: new challenges. Curr Trends Concerns Infect Dis. 2020;191-215.

12. Breymann C, Auerbach M. Iron deficiency in gynecology and obstetrics: clinical implications and management. Hematol Am Soc Hematol Educ Program. 2017;2017(1):152-9.

13. Tandon R, Jain A, Malhotra P. Management of iron deficiency anemia in pregnancy in India. Indian $\mathrm{J}$ Hematol Blood Transfus. 2018;34(2):204-15.

14. World Health Organization. The Clinical Use of Blood-Handbook. Geneva: World Health Organization; 2015.

15. World Health Organization. Blood safety and availability. Geneva: World Health Organization; 2020.

16. Lozano $\mathrm{M}$, Badawi $\mathrm{M}$. Indication for Transfusion of Blood components. ISBT Sci Ser. 2020;15:320-30.

17. Akinlusi FM, Rabiu KA, Durojaiye IA, Adewunmi AA, Ottun TA, Oshodi YA. Caesarean delivery-related blood transfusion: correlates in a tertiary hospital in Southwest Nigeria. BMC Pregnancy Childbirth. 2018;18:24.

18. CS Benson, A Shah, SJ Stanworth, CJ Frise, H Spiby, SJ Lax, et al. The effect of iron deficiency and anaemia on women's health. Anaesthesia. 2021;76(S4):84-95.

\section{CONTRIBUTORS}

1. Nadia Kashif - Concept \& Design; Data Acquisition; Drafting Manuscript

2. Aneela Ambreen - Critical Revision; Supervision; Final Approval

3. Afshan Ahsan - Data Analysis/Interpretation 